\title{
Os Três Gerúndios: Uma Análise da Variação das Constantes Arquitetônicas
}

\author{
The three gerunds: An Analysis of the Variation of the Constants in Architecture
}

\author{
Verônica G. Natividade \\ Pontifícia Universidade Católica do Rio de Janeiro, Brasil \\ veronica.natividade@gmail.com
}

\begin{abstract}
This paper is a reflection on the directions that digital architectures have been taking due to their growing materialization achieved after the popularization of digital fabrication technologies. It aims to discuss some reformulations of the conceptual foundations of the architecture under the influence of digital design methodologies based on the concepts of forming, structuring and performing.
\end{abstract}

Keywords: Arquiteturas digitais; Teoria; Tectônica; Estudo da forma; Performance.

\section{Introducão}

O presente artigo é um reflexão sobre os rumos que as arquiteturas digitais têm tomado em função da sua crescente materialização graças à popularização de tecnologias de fabricação digital. Pretende discutir as reformulações das bases conceituais da arquitetura à luz das metodologias emergentes de concepção formal com base no digital de forming, structuring e performing.

\section{Teoria - Prática - Crítica em Recursão}

A teoria da arquitetura é um discurso sobre a prática e produção da disciplina, que aponta para seus grandes desafios (Nesbitt, 2006). Tem muitas interseções com a história, que estuda as obras do passado e com a crítica, que implica no julgamento ético e estético das obras (Montaner, 2007). Apesar de beber dessas duas fontes, a natureza especulativa, catalizadora e antecipatória da teoria denotam a distinção de sua natureza frente à história e à crítica, uma vez que a teoria tem o papel de oferecer soluções alternativas.

Para alcançar sua validação, a teoria não pode se prescindir da experiência de se colocar à prova por meio da prática e, consequentemente, se submeter à crítica, que por sua vez, não existe sem a teoria (Montaner, 2007). Ao longo da história da arquitetura é possível identificar a recorrência de certas problemáticas que demandaram tanto soluções conceituais, portanto teóricas, quanto físicas, portanto, no nível da prática. Enquanto as primeiras foram problematizadas pela filosofia, as últimas foram resolvidas à luz da tectônica (Nesbitt, 2006).

A tectônica no sentido de expressão material da arquitetura engloba o amplo espectro de assuntos que vão desde aspectos funcionais até aspectos físicos das obras, como organização espacial, manipulação de materiais construtivos, definição de relações e hierarquias entre partes do edifício e seus significados (Picon, 2010). Materializar a arquitetura, seja ela digital ou não, oferece desafios nem sempre antecipados pela teoria. Nesse sentido, materializar a arquitetura promove a revisão da teoria envolvida por meio de sua avaliação crítica.

No campo das arquiteturas digitais, a tarefa de costurar uma teoria com uma postura crítica a partir da observação de uma prática não está desassistida. Pesquisadores como Rivka Oxman e Branko Kolarevic têm se dedicado a investigar conceitos e conteúdos na tentativa de explicar em nível teórico a produção das arquiteturas digitais. Outros arquitetos têm se utilizado da observação de suas próprias experimentações práticas para testar e extrair conceitos para formular suas teorias. Greg Lynn, Marcos Novak, Peter Eisenman são pioneiros dessa tentativa.

Por se tratar de um movimento intimamente vinculado à tecnologia em constante evolução, inserida num contexto sóciocultural extremante complexo e mutante, as abordagens tanto teóricas quanto tectônicas são múltiplas, motivo pela qual as arquiteturas digitais são tratadas no plural (Dollens, 2002).

Muito além da simples renovação instrumental de métodos conceptivos e construtivos, as arquiteturas digitais possuem corpo teórico próprio cujas bases são respaldadas por inovações tecnológicas que emergiram nas últimas décadas, singularizando sua prática dentro do contexto geral da arquitetura (Oxman, 2005). Em função dessa unicidade, a materialização das arquiteturas digitais exigem não só uma revisão teórica como também novos instrumentos de análise crítica distintos dos convencionais (Oxman, 2006).

\section{Quesito: Evolução}

Ao longo dos cinquenta anos de experimentações do digital na arquitetura, as pesquisas privilegiaram a investigação de formas em total contraste com o vocabulário limitado do modernismo (Picon, 2010). Enquanto os primeiros usos do computador na arquitetura foram direcionados para a representação e 
visualização das formas concebidas analogicamente, a partir da década de 1980, arquitetos pioneiros como Marcos Novak, Greg Lynn, Peter Eisenman e Stephen Perrella se empenharam em estudar novas possibilidades formais com o auxílio dessa ferramenta emergente. Muitas teorias e conceitos foram desenvolvidos nesse período, geralmente embalados por textos filosóficos, como A Dobra de Deleuze e vocabulário emprestado das ciências, como por exemplo, fractais, complexidade e sistemas auto-organizados (Jencks, 2002).

Muito embora alguns desses arquitetos como Novak, Perrella e Lynn tenham declarado que a intenção de seus estudos era totalmente formal e especulativa, era difícil imaginar como formas tão complexas pudessem ser construídas. Essa dificuldade gerou certa resistência da maior parte dos arquitetos em aceitar o uso do computador para operações além da tarefa de representação, reduzindo essas arquiteturas à condição de 'modismo'.

No início dos anos 1990, as primeiras arquiteturas concebidas com base em processos digitais finalmente começaram a sair das telas dos computadores para ganhar materialidade. Ao romperem com o status de imagem para se tornarem obras construídas, essas arquiteturas deixaram de ser estudos formais especulativos para trilhar sua consolidação como movimento legítimo dentro da produção contemporânea de arquitetura (Oxman, 2006). Essa consolidação tem sido conquistada progressivamente por meio de formulações e especulações que, num primeiro momento, se detiveram exclusivamente ao campo conceitual. A medida que as tecnologias digitais de fabricação ficaram economicamente mais acessíveis, as experimentações no campo da prática começaram a avançar a passos largos, abrindo novos leques de discussão.

\section{Dos Bits ao Átomo}

Picon (2010) identificou que é na dimensão material das arquiteturas digitais, isto é, na sua tectônica onde reside o maior potencial de reformulação de conceitos, teoria, prática e crítica das arquiteturas digitais.

A conversão de bits para átomos, ou seja, a materialização das arquiteturas digitais, incorporou complexidades de novas ordens. Segundo Antoine Picon (2010), é justamente nessa aproximação entre processos de concepção digital e materialidade que pode estar a força motriz de mudanças nos rumos dessas arquiteturas. Para o autor, a tectônica no contexto da fabricação digital é um terreno fértil de inovações que pode incitar redefinições do papel do arquiteto e da natureza da sua produção. Com efeito, a possibilidade de materialização das arquiteturas digitais tem se tornando um viés de inovações e redefinições conceituais.

Enfrentar a materialidade de uma obra arquitetônica com toda a sua complexidade trouxe a reboque questões mais pragmáticas que as 'arquiteturas de computador' podiam se dar ao luxo de abster-se. Processos construtivos, interferências materiais, contexto urbano e até mesmo a relação mais direta com o usuário final daquela arquitetura não eram necessariamente questões abordadas pelos pioneiros do movimento.
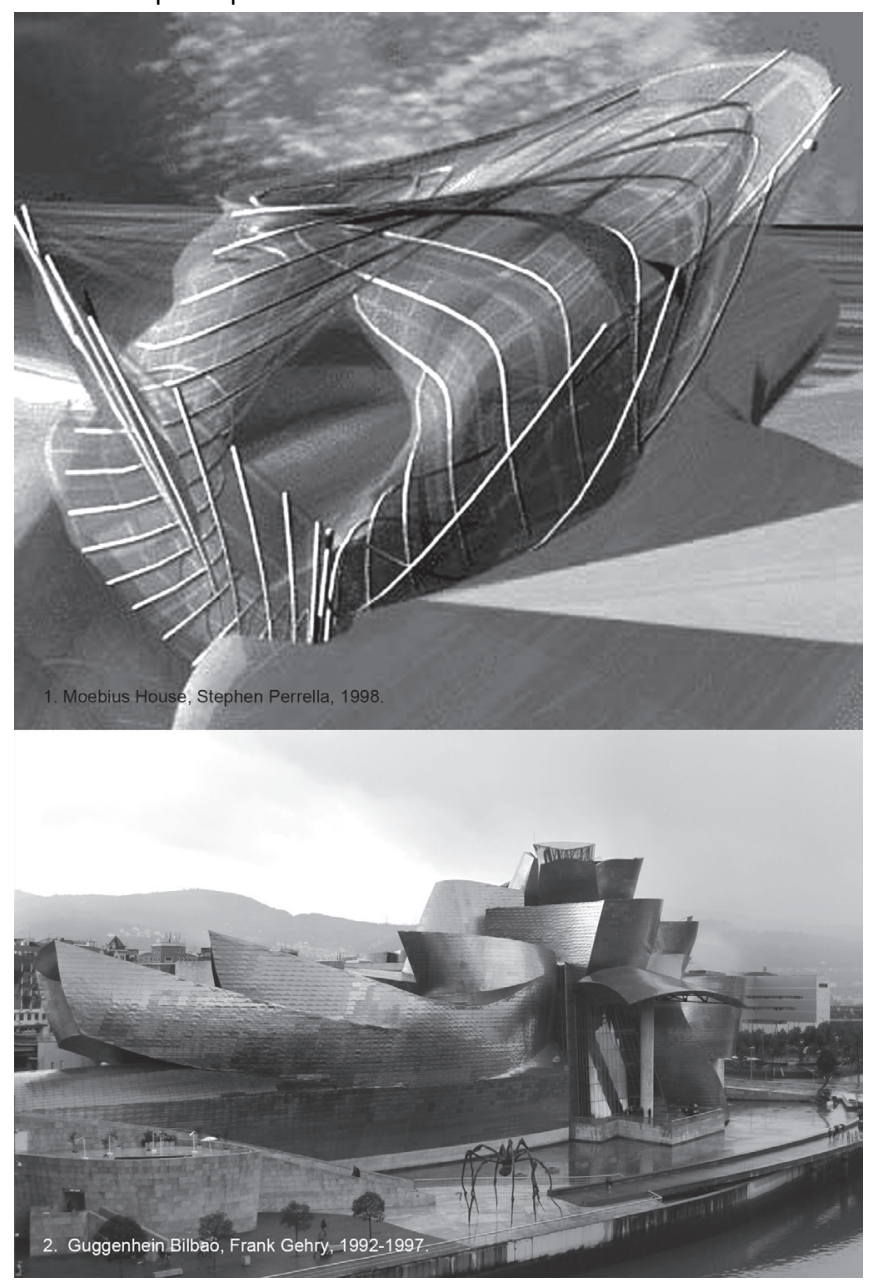

Figura 1: 1. Arquitetura de bits; 2 . O ovo de Colombo.

$\mathrm{Na}$ esteira desse movimento, observou-se a revisão da postura inicial estritamente formalista das primeiras práticas, cuja crítica era direcionada à atitude reducionista frente à arquitetura, que excluía aspectos mais complexos e abrangentes da concepção formal na arquitetura, baseando-se somente em parâmetros cuidadosamente selecionados, relacionados à imagem (Neuman \& Grobman , 2012). A inclusão de outros parâmetros na concepção formal das arquiteturas digitais, como aqueles derivados de aspectos programáticos e ambientais levaram o como fazer para além da questão unicamente metodológica, atingindo horizontes mais amplos. Conceitos arquitetônicos antes rechaçados voltaram à cena, como estética, ornamento, tectônica, ou foram repaginados, como a noção de performance (Hensel, 2013). Em paralelo, os processos de concepção digital parecem cada vez mais inseparáveis da materialidade da arquitetura (Picon, 2010).

A inclusão da materialidade na equação da concepção formal deflagrou uma crise da noção tradicional de tectônica (Picon, 2010). No desenrolar dessa crise, podem ser apontadas duas tendências ainda por formular: a retomada da discussão sobre função, que assume diversas facetas sob o conceito de 
performance; e a observação e incorporação de aspectos materiais no processo de concepção arquitetônica digital.

Os dois caminhos, contudo, não representam necessariamente uma bifurcação. Tampouco restringe a discussão aos aspectos pragmáticos das arquiteturas digitais, cuja gama de intenções é mais ampla, comportando também funções simbólicas. Ao contrário, as noções de forma, estrutura e materiais são cada vez mais inseparáveis (Oxman \& Oxman, 2010).

\section{Tríade ing ou os Três Gerúndios}

$\mathrm{Na}$ análise desse conteúdo conceitual, a pesquisadora Rivka Oxman (2005) identificou que as palavras-chave do discurso de arquitetos digitais - dinamismo, interatividade, adaptabilidade, hibridismo, animação, responsivo - não se aplicam somente a funções descritivas do edifício, mas como conteúdos conceituais significativos na concepção formal das obras.

Fundamentadas em técnicas exclusivamente digitais, essa arquiteturas ilustram mais precisamente um processo de se tornar algo e não uma representação no sentido convencional (Tierney, 2006). Seja através da noção de formation models (Oxman, 2006), information (Kolarevic \& Malkawi, 2005) ou form-finding (Kolareric, 2002), a forma deixa de ser um produto da manipulação direta sobre modelos digitais sofisticados para se tornar um produto de manipulação indireta num processo digital de emergência da forma. Em outras palavras, "a ênfase se desloca de fazer uma forma para encontrar uma forma baseada em diversas técnicas gerativas." (Oxman, 2006).

Dentro desses princípios, a forma não é dada a priori. Está em aberto, em fluxo, gerando certo grau de incerteza no momento de sua concepção. As ferramentas digitais empregadas são poderosas, permitindo a manipulação formal em alto grau de complexidade, gerando grande número de soluções possíveis. Esse processo denota uma ação, uma inflexão em gerúndio, introduzindo o conceito de form para forming, ou seja de forma para formando.

Kolarevic (2002) apontou que essa nova maneira de concepção formal implicaria na reaproximação entre arquiteto e canteiro, uma vez que os arquitetos digitais passariam a se envolver cada vez mais em aspectos materiais da arquitetura, como estrutura e propriedades físicas dos materiais construtivos. Com efeito, a aproximação entre arquitetos e engenheiros levou a uma nova inflexão na metodologia digital de concepção da forma. Ao encarar a materialização, as arquiteturas digitais deixaram de ser produtos de manipulações formais em gravidade zero para incorporar a estrutura como parte intrínseca do processo de concepção formal.

Dentro desse contexto, não faria sentido manter os princípios modernistas de separação entre estrutura e fechamento. A abordagem estritamente formalista do tipo "podemos desenhar qualquer forma que os engenheiros da Arup descobrirão a maneira de construí-la" (Kolarevic, 2002) tampouco foi mantida. Ao contrário, surgindo da mesma matriz, forma e estrutura se fundem, confundem e se misturam. Se o processo de geração da forma é um gerúndio, a concepção estrutural dentre dessas linhasguia também o é, introduzindo o segundo gerúndio: o princípio de structuring (Oxman \& Oxman, 2010).

O segundo desdobramento da materialização das arquiteturas digitais aqui levantado é a reconsideração do conceito de função. Como disciplina performativa, a arquitetura deve responder não só a critérios estéticos, mas também deve incorporar questões relativas à eficiência (Rahim e Jamelle, 2007). Enquanto as arquiteturas dos bits só acomodavam outros bits, as arquiteturas digitais agora materializadas se viram diante da tarefa de acomodar o usuário no espaço físico, adicionando novos layers ao nicho inicial de contestação e crítica.

No contexto das arquiteturas digitais, seria um contrassenso fundamentar a ênfase crescente sobre o desempenho do edifício na máxima 'a forma segue a função'. A lógica da forma como um produto da função é mecanizada, fundamentando-se principalmente nos aspectos utilitários da forma e não necessariamente endereçando a complexidade formal como produto cultural, social e político que a contemporaneidade exige (Neuman \& Grobman , 2012).

$\mathrm{Na}$ busca por soluções, uma das correntes mais fortes tem sido o design baseado em performance, que se esquiva tanto da aproximação formalista do design baseado na busca pela forma quanto da ameaça do "tecno-determinismo" (Meredith, Lasch \& Mutsuro, 2008), onde a arquitetura fica refém do software. Nas arquiteturas digitais, performance tem sido entendida como um princípio de projeto que se utiliza da simulação de parâmetros qualitativos e quantitativos prioritários ao qual o edifício deve responder, cujas análises auxiliam no processo de decisão de projeto (Kolarevic \& Malkawi, 2005).

A noção de performance é um campo em expansão que tem sido abordado de forma muito ampla. Seu significado abrange vários domínios, que vão desde o espacial, social e cultural até aspectos puramente técnicos, como estrutura, conforto ambiental, resistência de materiais. Atinge níveis maiores de eficácia exatamente quando atua sobre esse campo expandido, incorporando mais do que aspectos objetivos (Schumacher, 2011). A ênfase crescente no desempenho dos edifícios, englobando desde o contexto social, cultural e econômico até a construção física, tem influenciado processos e práticas de projeto na medida em que tem eliminado a distância entre geometria e análise, aparência e desempenho (Kolarevic \& Malkawi, 2005).

Desse campo de negociação entre desempenho e concepção formal, emerge o terceiro gerúndio: performing. No lugar das análises estáticas utilizadas nas abordagens clássicas de performance, o design baseado em performance no contexto das arquiteturas digitais sugere a manipulação de uma conjunção de 
fatores por meio da qual emerge uma forma (Hensel, 2013). A performance se torna performing (Somol, 1999).

Forming, structuring e performing não são metodologias auto excludentes. Ao contrário, podem ser fundidas para gerar novos conceitos, teorias e produtos, sem haver preferência ou domínio de uma sobre a outra. Sob esse ponto de vista, é "forma primeiro, estrutura primeiro, material primeiro" (Oxman in Oxman, 2010). Nesse contexto, o que seria chamado convencionalmente de estrutura também é a pele e o fechamento que também adiciona funções estéticas; o ornamento, totalmente reformulado, vai além da função decorativa, atuando como componente mediador da performance em conforto ambiental; a forma é manipulada em função e não por causa da função.

\section{(In)Constantes}

Se tentarmos explicar esse fenômeno pelo ponto de vista da teoria da arquitetura como sugere Picon (2010) e não da história do digital na arquitetura como o fez Carpo (2011), é possível encontrar algumas chaves que podem contribuir para a formulação de uma teoria da arquitetura com base no digital. Ao adentrar por esse caminho, esbarra-se inevitavelmente no questionamento sobre a raiz da estrutura conceitual da arquitetura - utilidade, estrutura e beleza (Eisenman, 1988). Objeto de análise exaustiva e tentativas diversas de destituição (Tschumi, 1996), substituição (Eisenman, 1988) ou priorização de um elemento sobre o outro (Novak, 1988), o deleite visual, a inexorável materialidade da arquitetura e a adequação do espaço parecem permanecer como preocupações primordiais do arquiteto, independentemente do processo metodológico, da mídia ou da ferramenta adotados.

Com o amadurecimento das arquiteturas com base no digital é possível observar que as soluções dadas para essas 'constantes' da arquitetura são diferentes de movimentos anteriores, endossando sua singularidade. A tectônica ganha novo fôlego por meio da integração entre arquitetos e engenheiros no que Rivka Oxman (2010) chamou de "novo estruturalismo"; a utilidade deixa de se limitar à questão programática para englobar o tema da sustentabilidade (Kolarevic \& Klinger, 2008) e performance (Picon, 2010); e, finalmente, o debate sobre a beleza, tema sempre em evidência, têm suscitado o questionamento sobre estética, trazendo à discussão conceitos como ornamento (Picon, 2010), estilo (Schumacher, 2011) e elegância (Rahim \& Jamelle, 2007).

Sabemos, contudo, que a concepção humanística tradicional do homem - o homem vitruviano, idealizado - não encontra mais ecos na cultura ocidental contemporânea. Por consequência, evocar ou abandonar a teoria clássica como nos movimentos arquitetônicos do século XX parece equivocado. No entanto, apesar de estar livre do mundo unitário da tradição clássica, a leitura arquitetônica permanece prisioneira de uma série de dualidades dificilmente superáveis - abstração e figuração;

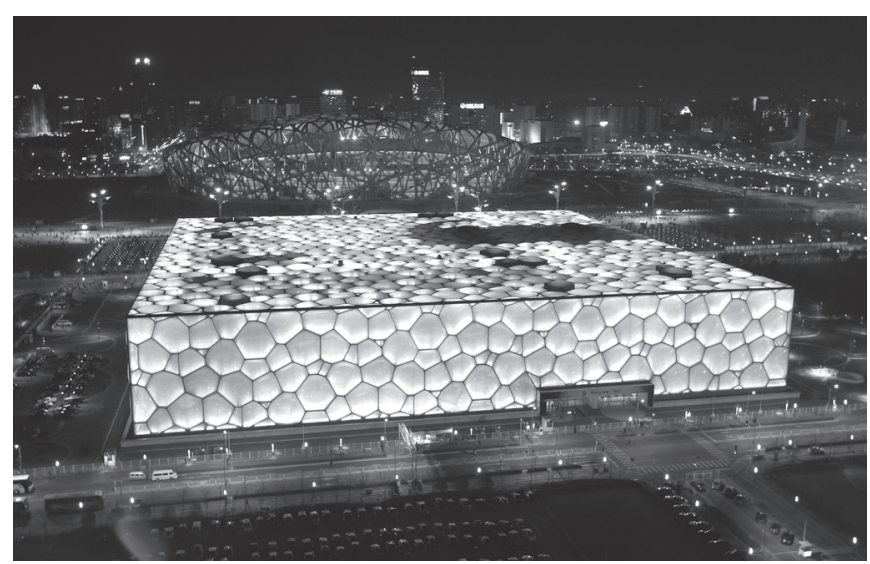

Figura 2: Cubo d'água e Ninho do Pássaro, Herzog \& de Meuron, 20032008: Nem isso nem aquilo.

tectônico e visual; unidade e multiplicidade; científico e artístico mas cada vez mais distante da complexa realidade da arquitetura.

Uma alternativa pode ser a reinterpretação e não o abandono dos fundamentos duradouros (Picon, 2010). Nesse contexto, não é correto propor uma correspondência direta e estanque entre utilidade $x$ performance; estrutura $x$ estruturalismo; beleza clássica $x$ digital. Ao contrário, um dos aspectos que tornam as arquiteturas digitais singulares reside exatamente na fusão entre estrutura e ornamento (Picon, 2010), forma e performance (Picon, 2010), tectônica e forma (Oxman, 2008), forma e materialidade (Kolarevic \& Klinger, 2008), alavancados pelos avanços na fabricação digital. No lugar de definir os limites de cada um desses elementos, como intentou Tschumi (1988), observa-se o movimento de borrá-los, dentro do que Eisenman (in Nesbitt, 2006) chamou de "duplicidade", onde não há dominância de um elemento sobre o outro. Ao contrário, existe uma estrutura de equivalências entre aspectos, onde impera a incerteza e a nãohierarquia. Essa (não)estrutura revela uma nova condição de "estar entre" (Eisenman in Nesbitt, 2006), onde dois elementos podem se juntar para formar um terceiro que não possui uma imagem forte; "é quase isso ou quase aquilo, mas que também não é nem uma coisa nem outra" (Eisenman in Nesbitt, 2006).

\section{(In)Conclusões}

Se não existe arquitetura sem textos (Tschumi, 1996), a materialização das arquiteturas digitais tornou ainda mais urgente a necessidade de formular teorias direcionadas ao fenômeno do digital na arquitetura e a consequente revisão dos instrumentos da sua análise.

A dimensão material, por sua vez, inclui uma dimensão social, ao nível do usuário, que também deve ser objeto de atenção. "Arquitetura sem conteúdo de alcance público e sem direção espiritual perde seu caminho" (Jencks, (2002). Técnicas e tecnologias podem influenciar a manipulação de parâmetros, mas como Lynn aponta, não há nenhum conteúdo ideológico ou político nessa ação. Talvez um dos maiores desafios para a arquitetura digital seja elaborar um argumento convincente para a 
cena política e social no tocante à relevância da complexidade da arquitetura digital, elevando o processo de formation para níveis mais profundos do que a mera form-finding.

\section{Referências}

Oxman, R. \& Oxman, R. (2010). The new structuralism. AD Architectural design, 206.

Rahim, A. \& Hina, J. (2007). Elegance. AD Architectural design, 185.

Oxman, R. (2005). Conceptual content of digital design. eCCADe, 23.

Oxman, R. (2008). Conceptual content of digital design. eCCADe, 23.

Oxman, R. (2006). Theory and design in the first digital age. Design Studies, 27 (3), pp. 229-266.

Picon, A. (2010). Digital culture in architecture. Basel, Switzeland: Birkhauser.

Grobman, Y J. (Editor) \& Neuman, Eran (Editor). (2012) Performalism: Form and Performance in Digital Architecture.

Kolarevic, B. (2002) Architecture in digital age: design and manufacturing. Nova York, NY. Spon Press.
Kolarevic, B. \& Klinger, K.. (2008). Manufacturing Material Effects: Rethinking Design and Making in Architecture. Nova York, NY. Spon Press.

Meredith, M. (Autor e editor); Lasch, A. (Editor) \& Sasaki, M. (Editor) (2008). From control to design: Parametric/Algorithmic Architecture. Barcelona, Espanha: Actar-D.

Kolarevic, B. \& Malkawi. A. M. (2005) Performative architecture. Nova York: Spon Press.

Jencks, C. (2002). New paradigm in architecture. Londres: Yale University Press.

Tschumi, B. (1988). Architecture and disjunction. The MIT Press.

Schumacher, P. (2011). The autopoiesis of architecture: A new framework for architecture. United Kingdom: John Wiley \& Sons.

Montaner, J. M. (2007). Arquitetura e crítica. Barcelona, Espanha: Gustavo Gili.

Dollens, D. (2002). De lo digial a lo analogico. Barcelona, Espanha: Gustavo Gili. 